\title{
Genetic Analysis of Needle Morphological and Anatomical Traits among Nature Populations of Pinus Tabuliformis
}

\author{
Mei Zhang ${ }^{1}$, Jing-Xiang Meng ${ }^{1}$, Zi-Jie Zhang ${ }^{1}$, Song-Lin Zhu ${ }^{2} \&$ Yue $\mathrm{Li}^{1}$ \\ ${ }^{1}$ National Engineering Laboratory for Forest Tree Breeding, Key Laboratory for Genetics and Breeding of Forest \\ Trees and Ornamental Plants of Ministry of Education, College of Biological Sciences and Technology, Beijing \\ Forestry University, Beijing 100083, China \\ ${ }^{2}$ The Forestry Bureau of Xixian, China \\ Correspondence: Mei Zhang, College of Biological Sciences and Technology, Beijing Forestry University, \\ Beijing 100083, China. E-mail: liyue@ bjfu.edu.cn
}

Received: December 6, 2016

Accepted: January 10, 2017 Online Published: January 21, 2017

doi:10.5539/jps.v6n1p62

URL: http://dx.doi.org/10.5539/jps.v6n1p62

\begin{abstract}
The morphological and anatomical traits of needles are important to evaluate geographic variation and population dynamics of conifer species. Variations of morphological and anatomical needle traits in coniferous species are considered to be the consequence of genetic evolution, and be used in geographic variation and ecological studies, etc. Pinus tabuliformis is a particular native coniferous species in northern and central China. For understanding its adaptive evolution in needle traits, the needle samplings of 10 geographic populations were collected from a $30 \mathrm{yr}$ provenience common garden trail that might eliminate site environment effect and show genetic variation among populations and 20 needle morphological and anatomical traits were involved. The results showed that variations among and within populations were significantly different over all the measured traits and the variance components within population were generally higher than that among populations in the most measured needle traits. Population heritabilities in all measured traits were higher than 0.7 in common garden sampling among populations. Needle traits were more significantly correlated with longitude than other factors. First five principal components accounted for $81.6 \%$ of the variation with eigenvalues greater than 1; the differences among populations were mainly dependent on needle width, stomatal density, section areas of vascular bundle, total resin canals, and mesophyll, as well as area ratio traits. Ten populations were divided into two categories by Euclidean distance. Variations in needle traits among the populations have shown systematic microevolution in terms of geographic impact on P. tabuliformis. This study would provide empirical data to characterize adaptation and genetic variation of $P$. tabuliformis, which should be more available for ecological studies.
\end{abstract}

Keywords: genetic structure, needle, morphological and anatomical traits, geographic population, Pinus tabuliformis

\section{Introduction}

Pinus tabuliformis is a native conifer species in northern and central China. It survived from the quaternary glacial with complex genetic components and climate factors widely changed in its distributions (Hewitt, 2000; Chen, 2007; Guo, 2008). Significantly variations among nature populations in P. tabuliformis have been reported on growth, wood property, physiology and propagation traits (Mao et al., 2009, Mao et al., 2011; Xu et al., 1991; Yuan et al., 2014; Niu et al., 2013; Yang et al., 2015). Evidences from molecular have indicated the genetic differentiation among populations bounded up with the geographic distance (Chen, 2007; Wang, 2010; Gao, 2009). Like other plant in temperate arid steppe zone, $P$. tabuliformis have formed phenotypic characters to resist lower temperature, water depletion and light conditions (Zhang, 2010; Liu, 2012).

Needle is the most vigorous assimilation organs for conifer species, and the morphological and anatomical traits of needle are important references to plant taxonomy (Anna K. et al., 2013; Xing, 2014; Huang, 2016). Needle traits are closely associated with physiological and functional attributes of plants including photosynthesis, respiration, water metabolism, nutritional status, as well as stress resistance (Oleksyn et al., 1997; Eguchi et al., 2004; Wu, 2007; Mao et al., 2012). Phenotypic variations of needle morphological and anatomical characteristics were considered the results in physiological and adaptive genetic evolution (Anna K. et al., 2013; 
Balkrishna et al., 2014), and have been widely used as available indicators in geographic variation, phylogenesis and evolutionary studies (Cole et al., 2007; Xing, 2014; Melville, 2002, B. Nikolić et al., 2013; Androsiuk Piotr et al., 2011; K. Boratynska et al., 2009).

However, phenotypic variations of needle traits should be influenced by both environment and genetic impacts (Li, 2009; Xu,1991; Cole et al., 2008) in studies with samples from natural forests within species (Legoshchina et al., 2013; Michael et al., 2012), hardly tell the amount of genetic or environment contributions and limit in explaining the real effects on changes among populations. Variations of needle traits from population samples based on common garden trail could provide the genetic contributions among populations. The research and analysis of $P$. tabuliformis mainly involve the natural distribution characters of needles, and results that might be limited because of environmental variations at different population sites (Nikolić et al., 2013; Xing et al., 2014). In this study, we collected the needle samples from a $30 \mathrm{yr}$ provenience common garden trail with ten populations in P. tabuliformis in order to eliminate environment effects on needle traits among populations. The objectives of this study were to (1) reveal the variations in needle morphological and anatomical traits among populations; (2) illustrate the variations in needle traits among individuals within population; (3) evaluate the genetic and environment impacts on phenotypic variation for each needle trait; and (4) clarify the phylogenetic relationships among populations. This study provides theoretical and methodological reference for the conservation biology of populations in the coniferous morphological variation, ecological adaptability, system evolution and population genetics. Provide the basis for the use of coniferous morphological traits in each study area.

\section{Materials and Methods}

\subsection{Sample Populations}

Ten geographic populations, located in typical habitat of P. tabuliformis, were involved (Fig. 1) in our experiment. Ten populations are as follows: Heilihe, Inner Mongolia(HLH); Dongling, Heibei(DL); Lingkongshan, Shanxi(LKS); Guandishan, Shanxi(GDS); Shangzhuang, Shanxi(SZ); Nanyang, Henan(NY); Luonan, Shannxi(LN); Shuanglong, Shannxi(SL); Xiaolongshan, Gansu(XLS); Huzhu, Qinghai(HZ).

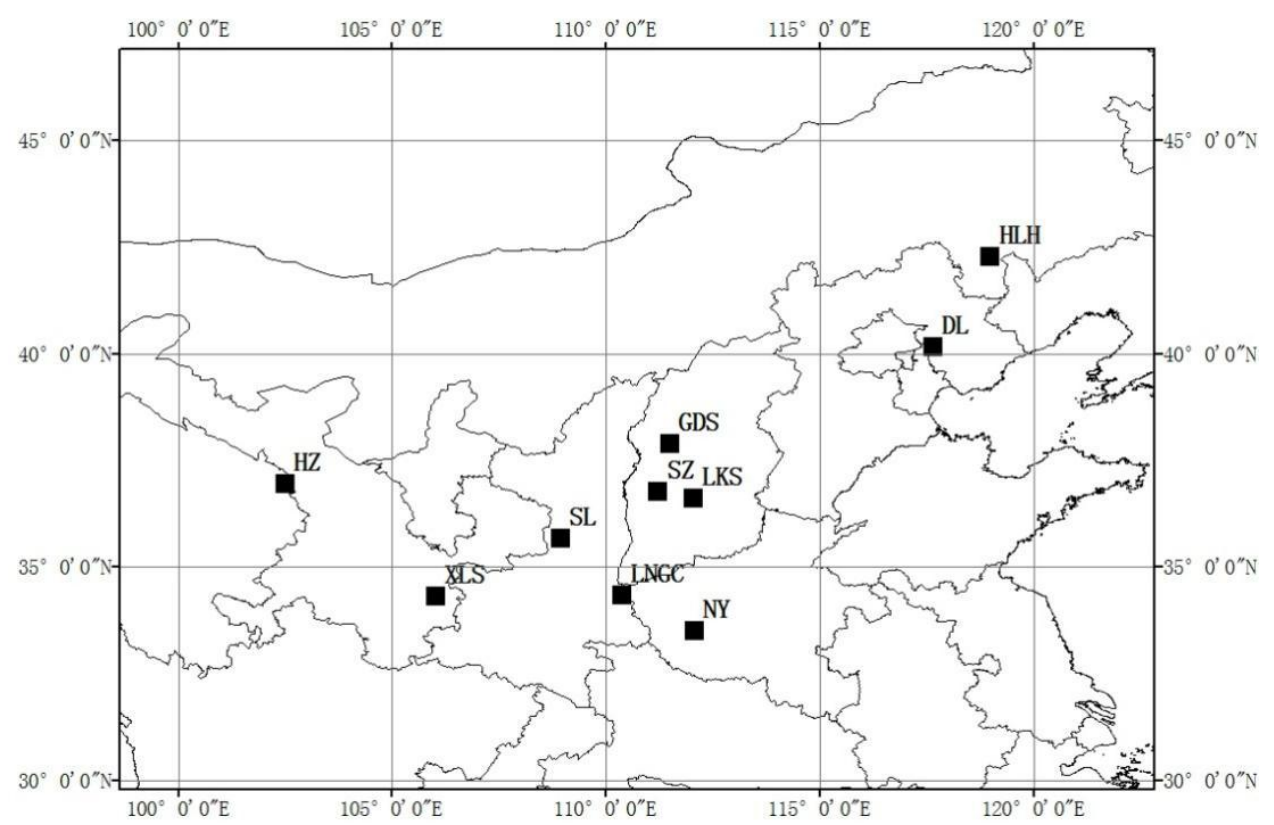

Figure 1. Location of ten P. tabuliformis populations sampled in North China

The environmental information of sampled populations is shown in Table 1. The annual mean temperatures and precipitations in each geographic location of populations were obtained from www.worldclim.com (Hijmans et al., 2005). 
Table 1. Sampling populations of P. tabuliformis

\begin{tabular}{llllllc}
\hline Population & Sample size & Longitude $\left({ }^{\circ} \mathrm{E}\right)$ & Latitude $\left({ }^{\circ} \mathrm{N}\right)$ & Altitude $(\mathrm{m})$ & Annual mean temperature $\left({ }^{\circ} \mathrm{C}\right)$ & Annual precipitation $(\mathrm{mm})$ \\
\hline HZ & 29 & $102^{\circ} 28^{\prime}$ & $36^{\circ} 58^{\prime}$ & 2300 & 2.4 & 443 \\
XLS & 21 & $106^{\circ} 00^{\prime}$ & $34^{\circ} 20^{\prime}$ & 1630 & 8.5 & 663 \\
NY & 14 & $112^{\circ} 03^{\prime}$ & $33^{\circ} 32^{\prime}$ & 810 & 12.6 & 776 \\
LNGC & 12 & $110^{\circ} 21^{\prime}$ & $34^{\circ} 21^{\prime}$ & 1220 & 10.0 & 720 \\
HLH & 25 & $118^{\circ} 58^{\prime}$ & $42^{\circ} 17^{\prime}$ & 1300 & 7.6 & 360 \\
GDS & 19 & $111^{\circ} 29^{\prime}$ & $37^{\circ} 54^{\prime}$ & 1500 & 1.5 & 561 \\
SL & 25 & $108^{\circ} 56^{\prime}$ & $35^{\circ} 41^{\prime}$ & 1650 & 10.2 & 543 \\
LKS & 13 & $112^{\circ} 02^{\prime}$ & $36^{\circ} 37^{\prime}$ & 1665 & 5.6 & 604 \\
SZ & 13 & $111^{\circ} 12^{\prime}$ & $36^{\circ} 46^{\prime}$ & 1660 & 6.2 & 545 \\
DL & 14 & $117^{\circ} 38^{\prime}$ & $40^{\circ} 11^{\prime}$ & 200 & 10.6 & 587 \\
\hline
\end{tabular}

\subsection{Field Experimental Design}

The common garden test of proveniences in P. tabuliformis was conducted in Xixian, Shanxi province $\left(111^{\circ} 10^{\prime} \mathrm{E}\right.$, $36^{\circ} 48^{\prime} \mathrm{N}$ ), the distribution central of the species and represented the general environmental conditions of the species. The experiment was established in 1981 with 2a seedlings from ten nature populations from the central to the edge of geographic distribution regions. A Randomized Complete Block Design (RCBD) with 6 blocks (replication), 24-individuals rectangular plot was set for the trail, $2 \mathrm{~m} \times 2 \mathrm{~m}$ in planting space. However, the remaining plants for each population were varied after $30 \mathrm{yr}$ nature selection. Needle samples from the provenience test were collected in September on 30yr plants in 2011, 11-30 individual trees for each population were involved from randomized sample trees. For each plant, 3 needles would be randomly selected for analysis. We examined a total of 20 traits involving morphology, anatomy and ratio of needle structures (Table 2). All the traits were adaptive- related and have been reported in previous researches (Huang et al., 2016; Xing et al., 2014; Zhao et al., 2008).

\subsection{Measurement of Needle Traits}

Twenty needle traits were measured according to Xing's work (Xing et al., 2014), including 16 directly measured morphological and anatomical traits and four area-ratio indices (the ratios between needle organizational structures in needle cross sections) (Table 2).

(1) Morphological traits (Fig. 2A): seven morphological traits were measured, including needle length (NL, $1 \mathrm{~cm}$ ); the width and thickness in the middle part of the needle (NW and NT, $0.1 \mathrm{~mm}$ ); the number of stomatal rows on the front and back sides of the needle (CSRN and FSRN, measured by stereomicroscope); the number of stomata rows(NSR, calculated as NSR=( FSRN+CSRN)); the mean number of stomata in $2 \mathrm{~mm}$ sections (SR2N, counted using Photoshop CS5 (Adobe Systems, Mountain View, CA) after photographing); the stomatal density on the convex surface of needle $(\mathrm{CSD}$, calculated as $\mathrm{CSD}=(\mathrm{SR} 2 \mathrm{~N} \times \mathrm{CSRN}) /(2 \times \mathrm{NW})))$; and the mean stomatal density of the needle $(\mathrm{MSD}$, calculated as MSD $=(\mathrm{SR} 2 \mathrm{~N} \times(\mathrm{CSRN}+\mathrm{FSRN})) /(2 \times 2 \times \mathrm{NW}))$.

(2) Anatomical traits: The needles were sliced into cross sections in the middle part by hand (Xu and Tao 2006) and then observed under a microscope (BA2100; Motic, Xiamen, China). Vascular bundles, resin canals, and mesophyll were the measured tissues to assess the abilities of substance transduction, stress tolerance, and organic synthesis of needles. A total of 11 anatomical traits (Fig. 2B) were measured by using Motic Images Plus 2.0 software, including vascular bundle width (VBW, $0.001 \mathrm{~mm}$ ); vascular bundle thickness (VBT, $0.001 \mathrm{~mm}$ ); vascular bundle area (VBA, $0.001 \mathrm{~mm}^{2}$ ); resin canal number (RCN); total resin canal area (RCA, $0.001 \mathrm{~mm}^{2}$ ); needle section area (NSA, $0.01 \mathrm{~mm}^{2}$ ); and mesophyll area (MA, $0.01 \mathrm{~mm}^{2}$, calculated as MA=NSA-VBA-RCA).

(3) Area ratio traits (indices): four ratio traits of comparative area between different organizational structures in needle cross sections were measured, including the ratio of mesophyll area/vascular bundle area (MA/VBA); the ratio of mesophyll area/resin canal area (MA/RCA); the ratio of vascular bundle area/resin canal area (VBA/RCA); and the ratio of mesophyll area/(resin canals and vascular bundles) area [MA/(VBA+RCA)] (Table 2). 
A

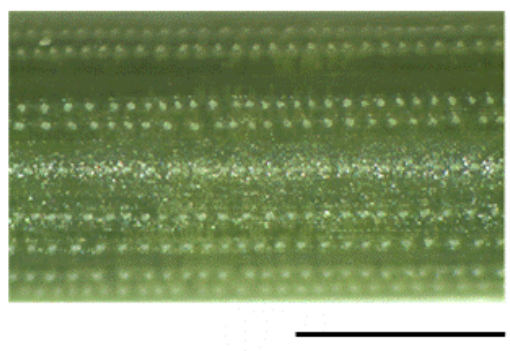

$0.5 \mathrm{~mm}$
B

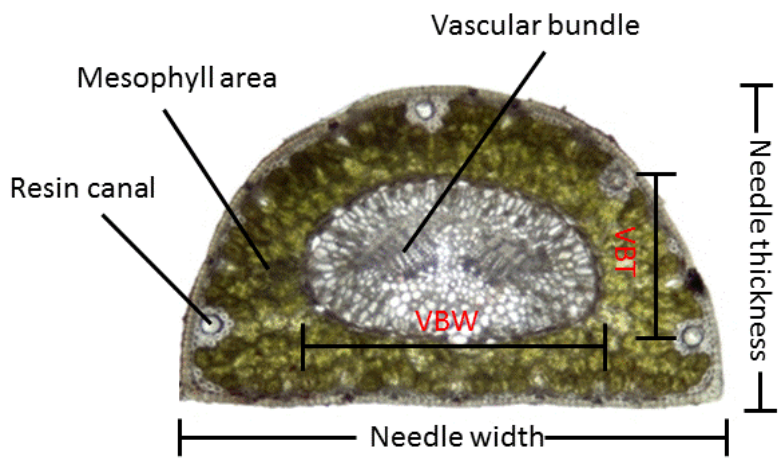

Figure 2. (A) stomatal rows on convex side of needle; $(\mathbf{B})$ cross-section of the needle by unarmed slice

Table 2. List of morphological and anatomical traits of needles for P. tabuliformis

\begin{tabular}{lll}
\hline Abbreviation & Unit & Traits \\
\hline NL & $\mathrm{cm}$ & Needle length \\
NW & $\mathrm{mm}$ & Needle width \\
NT & $\mathrm{mm}$ & Needle thickness \\
CSRN & No. & Number of stomatal rows on convex side of needle \\
FSRN & No. & Number of stomatal rows on flat side of needle \\
SR2N & No. & Mean number of stomata in a 2-mm-long section of needle \\
NSR & No. & Mean Number of stomata rows \\
CSD & No./mm2 & Stomatal density on the convex surface of needle \\
MSD & No./mm & Mean stomatal density of needle \\
VBW & $\mathrm{mm}$ & Vascular bundles width \\
VBT & $\mathrm{mm}$ & Vascular bundles thickness \\
VBA & $\mathrm{mm}$ & Vascular bundle area \\
RCN & No. & Resin canals number \\
RCA & $\mathrm{mm} 2$ & Total resin canals area (sum of areas for total resin canals on needle section) \\
NSA & $\mathrm{mm} 2$ & Needle section area \\
MA & $\mathrm{mm} 2$ & Mesophyll area \\
MA/VBA & - & Mesophyll area/Vascular bundle area \\
MA/RCA & - & Mesophyll area/Resin canals area \\
VBA/RCA & - & Vascular bundle area/Resin canals area \\
MA/(VBA +RCA) & - & Mesophyll area/(Resin canals area and Vascular bundle area) \\
\hline
\end{tabular}

\subsection{Statistical Analyses}

Means, variation coefficients (CVs) and standard deviations for each trait among the populations were estimated. Data from each single needle measurement were used to conduct variance analysis. The analysis of variance (ANOVAs) for each morphological and anatomical trait of needle was carried out by using a similar nested-linear model and estimates of variance components:

$$
y_{i j k}=\mu+p_{i}+T_{j(i)}+e_{i j k}
$$

In this analysis, yijk is observation value of sample needle; $\mu$ is the mean of experiment; $p_{i}$ is the effect of populations (random); $T_{j(i)}$ is the effect (random) of individual trees within populations; and $e_{i j k}$ is the residual among sampled needles (random). All analyses were conducted in the SPSS 20.0 (SPSS Inc., Chicago, IL) and R (R, The University of Auckland, New Zealand) software. Population heritability $\left(\mathrm{H}^{2}\right)$ of each trait was estimated as described in previous author in situ and common garden test respectively (Becker, 1992).

Principal components analysis (PCA) was applied to scale data and evaluate the underlying dimensionality of the variables. We used PCA with a standardized matrix containing data on measured traits. The PCA scores of the five components were used to calculate the species distance. All the multivariate statistical analyses were performed in R.

Phenotypic correlation was analyzed at the level of individual and population. Morphological and anatomical traits of needles with a correlation coefficient of $<0.8$ were used to do further analyses in order to minimize 
over-fitting of niche models by highly correlated traits and improve the interpretability of niche axes in the multivariate analyses.

Clustering analysis among populations of P. tabuliformis was performed using the Ward method in $\mathrm{R}$, and the Euclidean distance among populations was calculated from z-cores. The average values of each needle trait were used for cluster analysis. Fifteen correlational needle phenotypic traits [NL, NW, SR2N, CSRN, FSRN, MSD, RCN, RCA, VBA, NSA, MA, MA/VBA, MA/RCA, VBA/RCA, MA/ (VBA+RCA)] were chosen to conduct cluster analysis.

\section{Results}

It was common for P. tabuliformis to appear in two-needle fascicle. Cross-sections of needles were fan-shaped. Resin canals were marginal or near the vascular bundle. The number of resin canal almost is 7 10.

\subsection{Variations in Needle Morphological and Anatomical Traits among Populations}

The mean and CV values of 20 needle traits among each population were listed in Table 3. The variation coefficients of 20 needle traits among populations were between $1.99 \%$ (SR2N) and $19.26 \%$ (RCA). The CV of each trait was different, which showed different genetic differences among populations. The values of variation coefficient in section -area traits (RCA) and four ratio traits ( MA/RCA, MA/VBA, MA/(VBA+RCA) and $\mathrm{VBA} / \mathrm{RCA}$ ) were higher than $10 \%$, meaning that there were larger phenotype variations among populations on those traits, while the morphological traits (NL, NT, NW,SR2N) and VBT were less than 5\%. This means that there were smaller phenotype variations among populations on these traits, and anatomic traits were in moderate phenotype variation in general. 
Table 3. Mean values and variability coefficient (\%) analysis of needle characters in each P. tabuliformis population

\begin{tabular}{|c|c|c|c|c|c|c|c|c|c|c|c|c|}
\hline \multirow{2}{*}{ Traits $^{\mathrm{a}}$} & \multirow{2}{*}{$\begin{array}{c}\text { HZ } \\
\text { Mean }\end{array}$} & \multicolumn{3}{|r|}{ XLS } & \multicolumn{2}{|r|}{ NY } & \multirow{2}{*}{\multicolumn{2}{|c|}{$\mathrm{CV}$}} & \multicolumn{2}{|c|}{ LNGC } & \multicolumn{2}{|l|}{ HLH } \\
\hline & & \multicolumn{2}{|c|}{$\mathrm{CV}^{\mathrm{b}}$} & Mean & $\mathrm{CV}$ & Mean & & & Mean & $\mathrm{CV}$ & Mean & $\mathrm{CV}$ \\
\hline $\mathrm{NL}$ & 10.87 & \multicolumn{2}{|c|}{16.63} & 11.68 & 15.30 & 10.40 & \multicolumn{2}{|l|}{13.51} & 10.53 & 12.77 & 10.76 & 13.52 \\
\hline NT & 0.67 & \multicolumn{2}{|c|}{15.09} & 0.64 & 16.85 & 0.65 & \multicolumn{2}{|l|}{11.92} & 0.66 & 16.52 & 0.74 & 17.32 \\
\hline NW & 1.27 & \multicolumn{2}{|c|}{12.83} & 1.25 & 12.67 & 1.31 & \multicolumn{2}{|l|}{9.81} & 1.28 & 10.29 & 1.37 & 13.59 \\
\hline FSRN & 6.86 & \multicolumn{2}{|c|}{24.86} & 7.13 & 23.97 & 7.55 & \multicolumn{2}{|l|}{27.17} & 7.39 & 24.05 & 8.25 & 23.41 \\
\hline CSRN & 7.64 & \multicolumn{2}{|c|}{23.60} & 7.89 & 24.00 & 8.33 & \multicolumn{2}{|l|}{26.06} & 8.86 & 26.59 & 8.99 & 22.66 \\
\hline NSR & 14.51 & \multicolumn{2}{|c|}{16.88} & 15.02 & 14.38 & 15.88 & \multicolumn{2}{|l|}{20.64} & 16.25 & 13.75 & 17.24 & 15.75 \\
\hline SR2N & 20.53 & \multicolumn{2}{|c|}{7.86} & 20.29 & 8.23 & 21.36 & 9.18 & & 19.97 & 8.67 & 20.77 & 6.65 \\
\hline CSD & 62.94 & & & 65.38 & 30.70 & 68.91 & 30.44 & & 70.30 & 31.56 & 69.33 & 28.36 \\
\hline MSD & 59.60 & & & 62.04 & 22.10 & 65.67 & 26.18 & & 64.27 & 19.63 & 66.56 & 23.32 \\
\hline $\mathrm{RCN}$ & 9.80 & & & 8.65 & 20.67 & 8.26 & 19.29 & & 8.53 & 13.29 & 7.63 & 23.79 \\
\hline $\mathrm{RCA}$ & 0.001 & & & 0.001 & 43.57 & 0.001 & 32.89 & & 0.002 & 46.43 & 0.002 & 37.99 \\
\hline VBT & 0.31 & & & 0.32 & 20.39 & 0.31 & 17.19 & & 0.32 & 16.21 & 0.36 & 19.70 \\
\hline VBW & 0.65 & & & 0.64 & 14.25 & 0.66 & 14.23 & & 0.67 & 12.27 & 0.73 & 14.97 \\
\hline VBA & 0.17 & & & 0.16 & 30.96 & 0.17 & 29.66 & & 0.17 & 25.05 & 0.21 & 34.51 \\
\hline NSA & 0.68 & & & 0.64 & 27.52 & 0.68 & 20.62 & & 0.67 & 25.61 & 0.81 & 31.15 \\
\hline MA & 0.51 & & & 0.48 & 28.82 & 0.51 & 21.39 & & 0.49 & 28.50 & 0.60 & 32.22 \\
\hline MA/VBA & 3.37 & & & 3.10 & 26.72 & 3.28 & 29.95 & & 2.95 & 25.03 & 2.96 & 23.21 \\
\hline MA/RCA & 410.74 & & & 507.64 & 44.99 & 397.16 & 43.50 & & 385.91 & 66.77 & 354.47 & 52.61 \\
\hline VBA/RCA & 129.27 & & & 175.99 & 56.45 & 125.28 & 39.95 & & 135.26 & 75.52 & 123.27 & 55.40 \\
\hline MA/(VBA+RCA) & 3.34 & & & 3.07 & 26.49 & 3.24 & 29.81 & & 2.92 & 24.97 & 2.93 & 23.14 \\
\hline & GDS & & SL & & LKS & & $\mathrm{S}$ & & $\mathrm{D}$ & & Among & ulations \\
\hline Traits & Mean & $\mathrm{CV}$ & Mean & $\mathrm{CV}$ & Mean & $\mathrm{CV}$ & Mean & $\mathrm{CV}$ & Mean & $\mathrm{CV}$ & Mean & $\mathrm{CV}$ \\
\hline $\mathrm{NL}$ & 10.71 & 14.72 & 11.16 & 14.28 & 11.12 & 13.25 & 11.30 & 15.70 & 10.53 & 22.50 & 10.91 & 3.72 \\
\hline NT & 0.66 & 17.29 & 0.67 & 14.60 & 0.69 & 17.43 & 0.73 & 17.26 & 0.69 & 19.90 & 0.68 & 4.54 \\
\hline NW & 1.31 & 12.35 & 1.30 & 8.68 & 1.34 & 11.46 & 1.36 & 15.45 & 1.33 & 13.66 & 1.31 & 3.00 \\
\hline FSRN & 8.49 & 26.16 & 8.48 & 27.03 & 7.97 & 23.81 & 7.90 & 27.53 & 8.50 & 21.15 & 7.85 & 7.61 \\
\hline CSRN & 9.30 & 23.96 & 9.37 & 26.53 & 8.62 & 23.00 & 8.74 & 24.57 & 8.88 & 20.08 & 8.66 & 6.50 \\
\hline NSR & 17.79 & 16.28 & 17.85 & 19.37 & 16.59 & 11.63 & 16.64 & 18.00 & 17.38 & 14.49 & 16.51 & 6.84 \\
\hline SR2N & 20.42 & 7.96 & 21.01 & 10.25 & 20.26 & 6.28 & 20.74 & 8.69 & 20.33 & 9.82 & 20.57 & 1.99 \\
\hline CSD & 73.07 & 25.11 & 75.96 & 30.08 & 65.38 & 24.27 & 67.74 & 26.55 & 68.92 & 24.46 & 68.79 & 5.54 \\
\hline MSD & 70.16 & 20.36 & 72.62 & 25.09 & 63.00 & 14.84 & 64.60 & 20.93 & 67.31 & 19.04 & 65.58 & 5.84 \\
\hline $\mathrm{RCN}$ & 9.07 & 20.82 & 8.39 & 22.43 & 8.00 & 14.62 & 7.79 & 26.52 & 8.14 & 15.72 & 8.43 & 7.61 \\
\hline $\mathrm{RCA}$ & 0.002 & 35.19 & 0.002 & 46.03 & 0.002 & 42.36 & 0.002 & 39.55 & 0.002 & 45.64 & 0.002 & 19.26 \\
\hline VBT & 0.34 & 18.96 & 0.33 & 17.55 & 0.34 & 19.01 & 0.31 & 21.91 & 0.33 & 28.48 & 0.33 & 4.69 \\
\hline VBW & 0.71 & 13.54 & 0.68 & 21.36 & 0.75 & 15.64 & 0.67 & 19.54 & 0.67 & 23.20 & 0.68 & 5.15 \\
\hline VBA & 0.19 & 27.62 & 0.18 & 33.95 & 0.20 & 32.52 & 0.17 & 40.16 & 0.18 & 50.78 & 0.18 & 9.38 \\
\hline NSA & 0.69 & 26.73 & 0.69 & 21.05 & 0.74 & 28.73 & 0.79 & 30.99 & 0.73 & 32.15 & 0.71 & 7.70 \\
\hline MA & 0.50 & 29.01 & 0.51 & 20.14 & 0.53 & 30.02 & 0.62 & 31.05 & 0.55 & 31.16 & 0.53 & 8.77 \\
\hline MA/VBA & 2.69 & 22.55 & 3.21 & 47.82 & 2.78 & 38.93 & 3.98 & 25.82 & 3.47 & 36.07 & 3.18 & 11.87 \\
\hline $\mathrm{MA} / \mathrm{RCA}$ & 327.29 & 50.45 & 340.12 & 42.90 & 275.61 & 43.36 & 461.62 & 48.96 & 324.27 & 41.73 & 378.48 & 18.31 \\
\hline VBA/RCA & 123.27 & 43.24 & 114.87 & 42.24 & 108.71 & 52.41 & 120.84 & 51.51 & 102.49 & 44.36 & 125.92 & 15.91 \\
\hline $\mathrm{MA} /(\mathrm{VBA}+\mathrm{RCA})$ & 2.66 & 22.38 & 3.17 & 47.31 & 2.74 & 38.08 & 3.94 & 25.71 & 3.42 & 35.85 & 3.15 & 11.87 \\
\hline
\end{tabular}

${ }^{\mathrm{a}}$ See Table 2 for definitions of the traits; ${ }^{\mathrm{b}}$ Variation coefficients $(\%)$.

Results of ANOVA showed that variations in all 20 needle traits were significant within and among populations. It showed that the variation of needle traits was controlled by significant genetic effects, and the genetic diversity and abundance variation among populations in P. tabuliformis. The values of variance components among populations were changed from $3.65 \%$ to $16.47 \%$. The variance components of all traits were less than $17 \%$, meaning that the genetic contribution of population on phenotype of each trait was different among them. In each measured trait, the population heritability among populations of the morphological traits was greater than 0.70 , the anatomical traits were greater than 0.86 , and the ratio traits were greater than 0.88 .

\subsection{Variation in Needle Traits among Individuals within Population}

The average CV of each measured needle trait was from $22.81 \% \sim 40.89 \%$ in individuals within population. And the SZ population was the largest $(40.02 \%)$, which showed that the variation of the needle phenotype was abundant, and the diversity was high, while the NY population was the least (23.67\%).

All the measured needle traits in sampling have shown significant variations of individuals within population by analyzing each sample data respectively as well (Table 4). Results from ANOVA showed that variance 
components of needle traits among individuals within population were generally higher than those among populations. Needle traits variation is influenced by individual genetic.

Table 4. ANOVA for morphological and anatomical needle traits among and within populations of $P$. tabuliformis

\begin{tabular}{llllll}
\hline \multirow{2}{*}{ Traits $^{\mathrm{a}}$} & \multicolumn{5}{c}{ Variance component $/ \%$} \\
\cline { 2 - 6 } & $\mathrm{P}(9)^{\mathrm{b}}$ & $\mathrm{T}(175)^{\mathrm{c}}$ & $\mathrm{R}(370)^{\mathrm{d}}$ & $\mathrm{H}_{\mathrm{p}}^{2}$ & $\mathrm{CV}_{\mathrm{p}}$ \\
\hline NL & $4.64^{* *}$ & $64.45^{* *}$ & 30.91 & 0.84 & 3.72 \\
NT & $6.82^{* *}$ & $69.82^{* *}$ & 23.36 & 0.92 & 4.54 \\
NW & $5.66^{* *}$ & $68.29^{* *}$ & 26.05 & 0.89 & 3.00 \\
CSRN & $8.43^{* *}$ & $35.09^{* *}$ & 56.48 & 0.83 & 7.61 \\
FSRN & $7.80^{* *}$ & $39.95^{*}$ & 52.25 & 0.83 & 6.50 \\
NSR & $15.70^{* *}$ & $68.57^{* *}$ & 15.73 & 0.98 & 6.84 \\
CSD & $4.17^{* *}$ & $45.72^{* *}$ & 50.11 & 0.71 & 1.99 \\
MSD & $7.32^{* *}$ & $67.32^{* *}$ & 25.35 & 0.92 & 5.54 \\
SR2N & $3.65^{* *}$ & $52.16^{* *}$ & 44.19 & 0.70 & 5.84 \\
RCA & $16.47^{* *}$ & $52.25^{* *}$ & 31.28 & 0.95 & 19.26 \\
RCN & $13.94^{* *}$ & $62.21^{* *}$ & 23.85 & 0.96 & 7.61 \\
VBT & $5.19^{* *}$ & $64.03^{* *}$ & 30.78 & 0.86 & 4.69 \\
VBW & $7.81^{* *}$ & $68.25^{* *}$ & 23.94 & 0.93 & 5.15 \\
VBA & $6.73^{* *}$ & $68.52^{* *}$ & 24.76 & 0.91 & 9.38 \\
NSA & $7.10^{* *}$ & $70.33^{* *}$ & 22.58 & 0.92 & 7.70 \\
MA & $7.84^{* *}$ & $67.48^{* *}$ & 24.68 & 0.92 & 8.77 \\
MA/RCA & $10.88^{* *}$ & $48.91^{* *}$ & 40.21 & 0.91 & 11.87 \\
MA/VBA & $8.84^{* *}$ & $55.16^{* *}$ & 36.00 & 0.90 & 11.87 \\
VBA/RCA & $7.84^{* *}$ & $52.33^{* *}$ & 39.83 & 0.88 & 18.31 \\
MA/(VBA+RCA) & $8.98^{* *}$ & $55.12^{* *}$ & 35.9 & 0.90 & 15.91 \\
\hline
\end{tabular}

*Statistical significance at $\mathrm{P}=0.05$; * Statistical significance at $\mathrm{P}=0.01$; ${ }^{\mathrm{a}}$ See Table 2 for definitions of the traits; ${ }^{\mathrm{b}} \mathrm{df}=9$ for populations; ${ }^{\mathrm{c}}$ $\mathrm{df}=175$ for individuals within populations; ${ }^{\mathrm{d}} \mathrm{df}=370$ for error; We abbreviate individual and populations as ind and pop, respectively; $\mathrm{H}_{\mathrm{p}}^{2}$ is population heritability; $\mathrm{CV}_{\mathrm{P}}$ is coefficient of variation among populations.

\subsection{The Correlations between Needle Traits}

Based on analysis by population, NL, SR2N, MSD and MA in morphological traits have not shown significant correlation with other traits (Table 5), while NW was positively correlated with RCA, VBA, NSA and MA significantly, and CSRN was positively correlated with MSD only. VBA and RCD were positively correlated with NSA and MA significantly. These results showed that NL and the stomatal characteristics were independent from other traits in population level.

By individual trees, there were more correlation coefficients significantly between measured traits. The trends of correlation were similar for both population and individual tree level, and meant that the same genetic relation between measured needle traits existed in both genetic level. 
Table 5. Correlation coefficients between needle traits of P. tabuliformis

\begin{tabular}{|c|c|c|c|c|c|c|c|c|c|c|c|c|c|c|c|}
\hline Traits $^{\mathrm{a}}$ & NL & NW & FSRN & CSRN & SR2N & MSD & $\mathrm{RCN}$ & RCA & VBA & NSA & MA & $\begin{array}{l}\text { MA/ } \\
\text { VBA }\end{array}$ & $\begin{array}{l}\text { MA/ } \\
\text { RCA }\end{array}$ & $\begin{array}{l}\text { VBA/ } \\
\text { RCA }\end{array}$ & $\begin{array}{l}\mathrm{MA} /(\mathrm{VBA} \\
+\mathrm{RCA})\end{array}$ \\
\hline $\mathrm{NL}$ & 1.00 & -.18 & -.19 & -.26 & -.13 & -.21 & .03 & .31 & .16 & .03 & .03 & .16 & .48 & .51 & .17 \\
\hline NW & -.07 & 1.00 & $.64 *$ & .51 & .28 & .29 & $-.73^{*}$ & $.74 *$ & $.69 *$ & $.95 * *$ & $.86^{* * *}$ & .14 & .47 & $-.69^{*}$ & .13 \\
\hline FSRN & $-.11 * *$ & $.14^{* *}$ & 1.00 & $.89^{* *}$ & .17 & $.85^{* * *}$ & -.49 & $.69 *$ & $.65^{*}$ & .51 & .36 & -.13 & $-.66^{*}$ & $-.66^{*}$ & -.14 \\
\hline CSRN & -.08 & $.12 *$ & -.01 & 1.00 & .07 & $.88^{* * *}$ & .45 & .59 & .55 & .38 & .24 & -.23 & -.58 & -.54 & -.23 \\
\hline SR2N & -.01 & .01 & $.11 *$ & .06 & 1.00 & .35 & -.21 & -.08 & -.09 & .19 & .26 & .34 & .07 & -.21 & .33 \\
\hline MSD & -.08 & $-.41 * *$ & $.51^{* * *}$ & $.53^{* *}$ & $.46^{* *}$ & 1.00 & -.27 & .36 & .35 & .15 & .04 & -.16 & -.45 & -.42 & -.16 \\
\hline $\mathrm{RCN}$ & -.06 & $.3^{* * *}$ & -.04 & -.04 & .01 & $-.21 * *$ & 1.00 & -.47 & -.43 & $-.69^{*}$ & $-.65^{*}$ & -.16 & .16 & .30 & -.16 \\
\hline RCA & -.04 & $.33^{* *}$ & $.18^{* * *}$ & $.15^{* *}$ & -.03 & -.03 & -.07 & 1.00 & $0.87 * *$ & .61 & .41 & -.29 & $-.91 * *$ & $-.82 * *$ & -.31 \\
\hline VBA & $-.09 *$ & $.73 * *$ & $.18^{* * *}$ & $.15^{* *}$ & .01 & $-.22 * *$ & $.26 * *$ & $.33^{* *}$ & 1.00 & .60 & .34 & -.56 & $-.77 * *$ & -.51 & -.56 \\
\hline NSA & -.06 & $.92 * *$ & $.12^{* * *}$ & $.14^{* * *}$ & -.01 & $-.36^{* *}$ & $.26 * *$ & $.32 * *$ & $.80^{* * *}$ & 1.00 & $.96^{* * *}$ & .29 & -.27 & -.55 & .28 \\
\hline MA & -.04 & $.90^{* *}$ & $.09 * *$ & $.12 *$ & -.01 & $-.38 * *$ & $.23 * *$ & $.28 * *$ & $.63^{* * *}$ & $.97 * *$ & 1.00 & .54 & -.03 & -.46 & .54 \\
\hline MA/VBA & $.10^{*}$ & -.07 & $-.14 * *$ & -.07 & -.04 & $-.09 *$ & -.07 & $-.16^{* *}$ & $-.59 * *$ & -.08 & $.14^{* *}$ & 1.00 & .49 & -.12 & $.99 * *$ \\
\hline MA/RCA & .02 & $.19^{* *}$ & $-.13 * *$ & $-.08 *$ & .00 & $-.21 * *$ & $.2^{* *}$ & $-.68 * *$ & .05 & $.23 * *$ & $.29^{* * *}$ & $.22 * *$ & 1.00 & $.79 * *$ & .51 \\
\hline VBA/RCA & -.01 & $.19^{* *}$ & -.06 & -.05 & .03 & $-.15^{* *}$ & $.26^{* *}$ & $-.57 * *$ & $.37 * *$ & $.24 * *$ & $.17^{* * *}$ & $-.29 * *$ & $.82 * *$ & 1.00 & -.11 \\
\hline $\mathrm{MA} /(\mathrm{VBA}+\mathrm{RCA})$ & $.09 *$ & -.07 & $-.14 * *$ & -.07 & -.04 & $-.09 *$ & -.07 & $-.17 * *$ & $-.58 * *$ & -.08 & $.14^{* *}$ & $.97^{* *}$ & $.24 * *$ & $-.29 * *$ & 1.00 \\
\hline
\end{tabular}

${ }^{a}$ See Table 2 for definitions of the traits; Above diagonal line is the correlation coefficients among populations; Below diagonal line is the correlation coefficients within individuals; *Statistical significance at $\mathrm{P}=0.05$; * ${ }^{*}$ Statistical significance at $\mathrm{P}=0.01$.

\subsection{The Correlations between Needle Traits and Environmental Factors}

Results of correlation analysis between geological, meteorological factors and some major needle traits of populations in P. tabuliformis showed that there was more significant correlation of needle traits with longitude than other factors (Table 6). Among major needle traits, longitude was significant associated with NW, CSRN, FSRN, RCN, RCA, VBA, NSA and MA; and latitude promoted traits in NW, FSRN, RCA, VBA, NSA and MA for positively significant correlation. Elevation was negatively correlated with the stomata (FSRN, CSRN, SR2N, MSD) and area traits (RCA, VBA, NSA, MA). The annual average temperature and the annual precipitation had no significant correlation with the measured traits. The higher or moderate correlation coefficients estimated between geological, meteorological factors and population needle traits might reveal microevolution of needle traits among populations by environmental impact.

Table 6. Correlation coefficients between geological, meteorological factors and some major needle traits of population in $P$. tabuliformis

\begin{tabular}{llllll}
\hline Traits $^{\mathrm{a}}$ & Longitude & Latitude & Altitude & $\mathrm{Amt}^{\mathrm{b}}$ & $\mathrm{Ap}^{\mathrm{c}}$ \\
\hline NL & -0.443 & -0.203 & $0.575^{\#}$ & -0.218 & -0.153 \\
NW & $0.764^{*}$ & $0.664^{*}$ & -0.234 & -0.051 & -0.453 \\
CSRN & $0.596^{\#}$ & 0.345 & -0.341 & 0.111 & -0.118 \\
FSRN & $0.707^{*}$ & $0.554^{\#}$ & -0.441 & 0.063 & -0.252 \\
SR2N & 0.094 & -0.078 & -0.066 & 0.315 & -0.046 \\
MSD & 0.427 & 0.207 & -0.352 & 0.218 & -0.052 \\
RCN & $-0.774^{* *}$ & -0.307 & 0.478 & -0.512 & -0.019 \\
RCA & $0.644^{*}$ & $0.578^{\#}$ & -0.233 & -0.069 & -0.337 \\
VBA & $0.646^{*}$ & $0.695^{*}$ & -0.097 & -0.227 & -0.497 \\
NSA & $0.672^{*}$ & $0.739^{*}$ & -0.114 & -0.104 & $-0.615^{\#}$ \\
MA & $0.553^{\#}$ & $0.615^{\#}$ & -0.098 & -0.040 & -0.542 \\
MA/VBA & -0.083 & -0.033 & -0.062 & 0.199 & -0.062 \\
MA/RCA & -0.486 & -0.411 & 0.264 & 0.088 & 0.169 \\
VBA/RCA & -0.518 & -0.448 & 0.319 & 0.009 & 0.250 \\
MA/(VBA+RCA) & -0.089 & -0.038 & -0.058 & 0.199 & -0.059 \\
\hline
\end{tabular}

${ }^{\mathrm{a}}$ See Table 2 for definitions of the traits; ${ }^{\mathrm{b}}$ Annual Mean Temperature; ${ }^{\mathrm{c}}$ Annual Precipitation; ${ }^{*}$ Statistical significance at $\mathrm{P}=0.1 ; *$ Statistical significance at $\mathrm{P}=0.05 ; *$ Statistical significance at $\mathrm{P}=0.01$.

\subsection{Principal Component and Cluster Analysis on Needle Traits}

Principal component analysis (PCA) on needle traits revealed five principal components with eigenvalues $>1$. The five principal components accounted for $81.659 \%$ of the variation. Individually, the following traits NW, NT, NSA, VBW, VBT, VBA, and MA had high loadings in the first component, more than $|0.8|$ (Table 7). CSRN, NSR, CSD, MSD had high loadings in the second component, more than |0.6|. MA, MA/VBA, and MA/ (VBA+RCA) had high loadings in the third component, more than |0.5|. RCA, MA/RCA, and VBA/RCA were the main loading in the fourth component, more than $|0.7|$. FSRN, CSRN were the main loading in the fifth 
component, more than $|0.5|$. The main loadings in first, second, third and fourth component were different. Ten populations were not clearly distinguished from each other. All of them had broad distributions that covered almost all of the each other.

Ten populations were divided into two categories by cluster analysis (Fig. 3). Populations in HZ and XLS (in the west of populations) were clustered into one group. Populations in GDS, SL, NY, LNGC, SZ, LKS (the central populations) and HLH, DL (in the northeast populations), were clustered into another group.

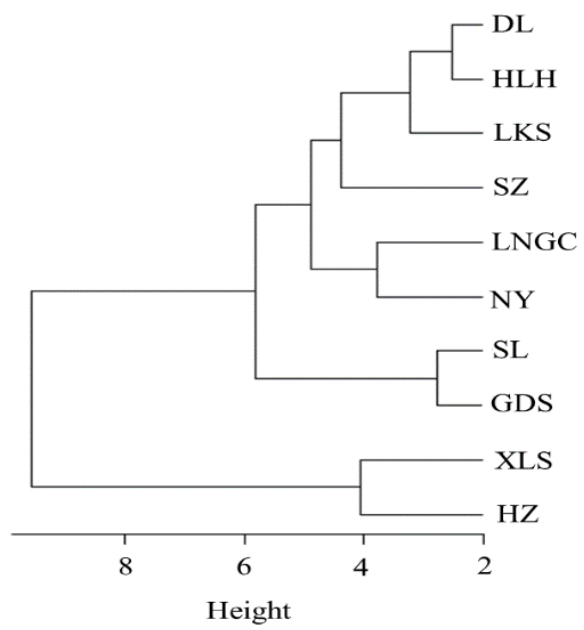

Figure 3. Cluster analysis based on needle traits in ten populations of $P$. tabuliformis

Table 7. Loadings on the first five components of needle traits in PCA in P. tabuliformis

\begin{tabular}{lllllll}
\hline Traits $^{\mathrm{a}}$ & Comp1 & Comp2 & Comp3 & Comp4 & Comp5 \\
\hline NL & -0.100 & -0.154 & 0.024 & -0.033 & -0.180 \\
NT & 0.891 & -0.093 & 0.296 & 0.031 & -0.047 \\
NW & 0.874 & -0.125 & 0.317 & -0.044 & 0.020 \\
FSRN & 0.171 & 0.480 & 0.116 & -0.014 & 0.822 \\
CSRN & 0.108 & 0.684 & 0.344 & 0.282 & -0.513 \\
NSR & 0.197 & 0.830 & 0.331 & 0.196 & 0.192 \\
SR2N & -0.027 & 0.313 & 0.069 & 0.255 & 0.141 \\
CSD & -0.302 & 0.754 & 0.187 & 0.352 & -0.410 \\
MSD & -0.339 & 0.847 & 0.121 & 0.290 & 0.196 \\
RCN & 0.332 & -0.190 & -0.068 & 0.197 & -0.016 \\
RCA & 0.340 & 0.342 & 0.200 & -0.761 & -0.080 \\
VBT & 0.894 & 0.131 & -0.186 & 0.006 & -0.047 \\
VBW & 0.894 & 0.180 & -0.235 & -0.053 & -0.033 \\
VBA & 0.947 & 0.151 & -0.189 & -0.008 & -0.041 \\
NSA & 0.929 & -0.110 & 0.334 & 0.013 & -0.015 \\
MA & 0.816 & -0.207 & 0.511 & 0.023 & -0.002 \\
MA/VBA & -0.414 & -0.415 & 0.794 & 0.055 & 0.051 \\
MA/RCA & 0.161 & -0.477 & 0.071 & 0.820 & 0.078 \\
VBA/RCA & 0.363 & -0.247 & -0.375 & 0.775 & 0.048 \\
MA/(VBA+RCA) & -0.411 & -0.420 & 0.794 & 0.064 & 0.052 \\
\hline
\end{tabular}

${ }^{\text {a }}$ See Table 2 for definitions of the traits.

\section{Discussion}

4.1 Variation Patterns and Genetic Structures of Needle Morphological and Anatomical Traits in Populations of P. Tabuliformis

Needle variations were considered the visual indicators to investigation of genetic variability and adaptive divergence (Wu, 1965; Balkrishna et al., 2014). All organizations have a special function of needles in conifer growth and metabolism physiological protection. The needle trait of mesophyll tissue is the main place of photosynthesis and fixed carbon assimilation of plant, vascular tissue is the main area of needles to divert water, inorganic salts and organic compounds, stomatal regulation of water transpiration and gas exchange with the environment of the channel, resin only with resistance. Populations of different environments in order to adapt to 
the local environment, the adaptability traits of its needle will have varying degrees of variation (Pensa M. et al., 2004). In order to adapt to the local environment, the adaptability traits of the needle will have different degree of variation. Understanding the stability of needle traits would be helpful for employing them in ecological and evolutionary studies (Xing, 2014). In this study, to test natural populations, $P$. tabuliformis is planted in the same environmental conditions so that variations of needle traits should be mainly impacted by genetic effects. The needles of population phenotypic variation are extremely rich, populations and individuals in a population were significant difference (Table 3 and 4). Variation components of needle traits within population were higher than that among general populations, which means the more genetic variations of needle traits existed in population in general. The morphological and anatomical needles traits within population diversity were higher than among populations, this is a kind of adaptability to complicated environment of $P$. tabuliformis. The needle traits were also significant variation among populations, reflected the extent to adapt to different environments. Different original provenances may lead the needle traits had higher population genetic variations. And this phenomenon was showed lately in seedling period of $P$. yunnanensis (Huang et al., 2016; Woo et al., 2002). It showed that the effect of environmental effects on plants can be inherited, and its distribution is closely related to the geographical environment, reproductive isolation and human activities. The morphological and anatomical needle traits were affected by the habitat change and natural selection in the distribution area, which reflected the adaptive strategy of population in the process of evolution. The morphological and anatomical characters of needles were affected by the habitat change and natural selection in the distribution area, which reflected the adaptive strategy of population in the process of evolution. The measured traits were much lower population contributions than individuals within population, and populations and individuals within population were significant difference. Phenotypic variation was determined by the effects of genetic variation, environmental variation, and the interactions between genetic and environmental factors (Rehfeldt, 1991).

Plant respiration, transpiration, and photosynthesis take place in the stomata (Batos et al., 2010). In this study, variance components of three stomatal traits (CSRN, FSRN, and SR2N) among populations were less than 10\%, and correlations between stomatal traits and other traits were low (Table 5). What this showed is that variation in stomatal traits among populations were relatively stable and independent. Variations in stomatal traits among populations were significant, probably due to the respiratory and photosynthetic pathway of the leaves, which are controlled by genetic factors(Zhang et al., 2012) and $\mathrm{HIC} \mathrm{CO}_{2}$ genes (Gray et al., 2000). In the process of needle formation, the $\mathrm{CO}_{2}$ level in the atmosphere was relatively stable, and the source of the variation was reduced. The excessive stomatal variation is not good for the growth and development of plants. Clearly, the environmental factors of provenance had a certain impact on genetic changes of stomatal density in population (Tiwari et al., 2013). In addition, needles length (NL) variation among geographical populations of pine is considered the result of ecology selection (Xiao, 2003). The length of the needles (NL) with little differences between conifer samples from different sources, indicating that needle length is mostly genetic-determined. Geographic populations at high-latitude and high-altitude usually have shorter needles, which should benefit coniferous plants resist snow pressure (López, 2010). Needles morphology and anatomy characteristics should be genetic determined (Eguchi, 2004; Li, 2013; Xing, 2014), and these indicators could be used as a reliable and efficient fast method to explore the genetic variation among geographical populations.

\subsection{The Relationship between Geographical Variation and Ecological Adaptability of Morphological and Anatomical Traits of Needles in Populations of P. Tabuliformis}

Differences in leaf traits reflect the adaptability of species in complex habitats, as well as the evolutionary history of species (Eo and Hyun, 2013). Genetic differentiation and environment divergence promote the phenotypic variation within species ( $\mathrm{Li}, 2013$; Kitajima, 2012). The influence of environment on different geographical populations is very significant. In our test, variations of needle traits in common garden sampling should represent the genetic differentiation among and within populations. The most variation components were observed within population, demonstrating that the differentiation among individuals is a major source of variation in P. Tabuliformis. Results from correlation analysis show that lots of needle traits are correlated with multiple environmental factors in different provenances (Table 6). MA/VBA presented a trend of decrease with increasing altitude, and increased with increasing temperature, which reflected the responses of needles to coldness in high altitude habitats. RCN was positively correlated with altitude, but negatively correlated with longitude, annual mean temperature and precipitation. Resin canals were considered to be the first line of defense stress (Eo and Hyun, 2013). Increasing the number of resin canals could help increase stress resistance in habitats with higher altitude. Likewise, increasing the number of resin canals could reduce the influence of torridity and drought. All the tested traits (except MA/RCA, VBA/RCA) were negatively correlated with annual precipitation. Correlation between traits and precipitation was generally higher than temperature, which meant 
precipitation was the limitation factor for the needle growth. Correlation between needle traits and longitude generally higher, indicating needle traits are relatively sensitive to longitude factor comprehensive effect, in other words phenotypic variation of $P$. tabuliformis showed variation pattern with longitude based on spatial distribution. Correlation analysis showed that most needle indicators increased from southwest to northeast, which is accordance with the distribution of water and heat in winter conditions. For previous research, temperature and precipitation gradual changed with longitude and latitude should have a selection on the genetic variation of $P$. tabuliformis (Liang, 2008; Liu, 2012).

The higher values of estimated population heritability in all measured needle traits in common garden sampling indicated that significant genetic differences are existence between populations in P. tabuliformis (Table 4). Habitat divergence among geographical populations should promote the genetic differentiation of plant species. P. tabuliformis is widely distributed in the northern China, the same natural population habitat area difference, directly affected by local habitat, thus forming a local ecotype. These variations could reflect the geographic and ecological distribution trend of species to a certain extent.

\subsection{Impacts of Environmental Effects on the Evolution of P. Tabuliformis Populations}

The ability of a species or population to adapt to the environment depends on the level of genetic variation and the distribution pattern of genetic variation (Nobis, 2012). Genetic differentiation and environmental variation will promote the phenotypic variation of species (Yuan, 2014; Li, 2008).Common garden test is one of the most detect method to exam genetic differences among geographical populations (Xiao 2003). In previous studies, most of them were sampled under the nature forest, which could not be used to represent the genetic difference. Environmental factors in the original areas had important impacts on the growth of plants (Körner, 2007; Lavadinović et al., 2011). Schlichting (1986) found that the changes of phenotypes were in accordance with the changes in environmental gradients.

In this study, populations in the closer area were gathered into the same groups (Fig 3). Due to heterogeneity and independence of the habitats, directional selection played a main role during the process of differentiation in individual habitats(Sękiewicz et al., 2013). There were differences between populations in the east and west of the distribution center of $P$. tabuliformis. Previous studies with molecular markers divided the P. tabuliformis into distinct groups (Chen, 2009), while our results with the test samples got the similar results. Molecular studies have shown that the western populations maybe recolonize from the southern population after the Quaternary glaciation (Wang, 2009; Chen, 2009), while the eastern populations may have originated from a refuge (Guo, 2008). Populations in the northeastern (DL, HLH, LKS), central west (SL, GDS), southeastern (NY, LNGC) probably were originated in the late Quaternary glacial refuge different (Guo, 2008; Liang, 2006).

Different correlation coefficients of needle traits and habitat factors are observed. Correlation analysis showed that measurement values of the most needle traits increased from southwest to northeast, which is accordance with the distribution tendency of water and heat of population location. For previous research, temperature and precipitation gradual changed with longitude and latitude should have a selection on the genetic variation of $P$. tabuliformis (Liang, 2008; Liu, 2012). Environment effected should be dissected when we compared the results of correlation analysis. Elevation has a positive impact on NL and resin ducts indicator (RCN), but a negative effect on the vascular bundles and stomatal density. Average annual temperature has a negative impact on the morphological traits, resin ducts indicator and vascular bundle. Annual precipitation was negative effect on most needle traits except MA/RCA, VBA/RCA. In earlier research, needle variations are always supposed to be the ecological consequence, but in this study, a complex reason of mutation, genetic drift and evolutionary history should be used explained the different direction of environment effected and genetic tendency of $P$. tabuliformis.

\section{Conclusion}

In conclusion, all measured morphological and anatomical needle traits were significantly different in both population and individual genetic level, and genetic contributions of individuals within population were higher than among populations in most of traits. Phenotypic variation of needle traits is considered to be the consequence of genetic evolution and higher population heritability in all measured traits were estimated. The traits related with needle size in both morphology and anatomy decreased with annual precipitation. Variations of needle traits among populations have shown systematic microevolution trends by geographic impact on $P$. tabuliformis, which provide genetic basis for the utilization of needle traits in various research fields and help us to understand the genetic pattern of needle in future.

\section{Acknowledgements}

This research was funded by the Fundamental Research Funds for the Central Universities (NO. 


\section{ZCQ-SW-02).}

We would like to express our gratitude to the laboratory of forest tree breeding, Xixian Forestry Bureau,, Yu-Jie Huang, for their kind help.

\section{References}

Androsiuk, P., Kaczmarek, Z., \& Urbaniak, L. (2011). The morphological traits of needles as markers of geographical differentiation in European Pinus sylvestris populations. Dendrobiology, 65, 3-16.

Anna, K., Jasinska, \& Krystyna, Boratynska et al. (2013). Relationships among Cedrus libani, C. brevifolia and C. atlantica has revealed by the morphological and anatomical needle characters. Plant Syst Evol., 299, 35-48. https://doi.org/10.1007/s00606-012-0700-y

Balkrishna, G., Chunghee, L., \& Kweon, H. (2014) Leaf anatomy and its implications for phylogenetic relationships in Taxaceaes. Journal Plant Research, 127, 373-388. https://doi.org/10.1007/s10265-014-0625-3

Batos, B., Vilotić, D., Orlović, S., \& Miljković D. (2010). Inter and intra-population variation of leaf stomatal traits of Quercus robur L. in Northern Serbia. Archives of Biological Sciences, 62, 1125-1136. https://doi.org/10.2298/ABS1004125B

Becker, W. A. (1992). Manual of quantitative genetics. 5th ed. Academic Enterprises, Washington.

Boratynska, K., \& Bobowicz, M. A. (2001). Pinus uncinata Ramond taxonomy based on needle characters. Plant Syst. Evol., 227, 183-194. https://doi.org/10.1007/s006060170047

CHEN, K., et al. (2008). Phylogeography of Pinus tabuliformis Carr. (Pinaceae), a dominant species of coniferous forest in northern China. Molecular Ecology, 17(19), 4276-4288. https://doi.org/10.1111/j.1365-294X.2008.03911.x

Cole, K. L., Fisher, J., \& Arundel, S. T. (2008). Geographical and climatic limits of needle types of one- and two-needled pinyon pines. Journal of Biogeography, 35(2), 257-269.

Eguchi, N., Fukatsu, E., \& Funada, R. (2004). Changes in morphology, anatomy, and photosynthetic capacity of needles of Japanese larch (Larix kaempferi) seedlings grown in high $\mathrm{CO}_{2}$ concentrations. Photosynthetica, 42(2), 173-178. https://doi.org/10.1023/B:PHOT.0000040587.99518.a8

Eo, J. K., \& Hyun, J. O. (2013). Comparative anatomy of the needles of Abies koreana and its related species. Turkish Journal of Botany, 37, 553-560.

Gao, M. W. Æ. F. Genetic Variation in Chinese Pine ( Pinus tabuliformis ), a Woody Species Endemic to China. Biochem Genet, 2009.

Gray, J. E., Holroyd, G. H., Bahrami, A. R., Sijmons, P. C., \& Woodward, F. I. (2000). The HIC signalling pathway links $\mathrm{CO}_{2}$ perception to stomatal development. Nature, 408, 713-716. https://doi.org/10.1038/35042663

Guo, L., Huang, G., \& Wang, Y. (2008). Seasonal and Tissue Age Influences on Endophytic Fungi of Pinus tabuliformis (Pinaceae) in the Dongling Mountains, Beijing. Journal of Integrative Plant Biology, 50(8), 997-1003. https://doi.org/10.1111/j.1744-7909.2008.00394.x

Hewitt, G. M. (2000). The genetic legacy of the Quaternary ice ages. Nature, 405, 907-913. https://doi.org/10.1038/35016000

Hijmans, R. J., Cameron, S. E., Parra, J. L., Jones, P. G., \& Jarvis, A. (2005). Very high resolution interpolated climate surfaces for global land areas. International Journal of Climatology, 25, 1965-1978. https://doi.org/10.1002/joc.1276

Huang, Y. J., Mao, J. F., \& Chen, Z. Q. (2016). Genetic structure of needle morphological and anatomical traits of Pinus yunnanensis. Journal of Forestry Research, 27(1), 13-25. https://doi.org/10.1007/s11676-015-0133-x

Körner, C. (2007). The use of 'altitude' in ecological research. Trends in Ecology \& Evolution, 22, 569-574. https://doi.org/10.1016/j.tree.2007.09.006

Lavadinović, V., Miletić, Z., Lavadinović, V., \& Isajev, V. (2011). Variability in Magnesium Concentration in Needles of Different Douglas-Fir Provenances. Forestry, 17, 74-79.

Legoshchina, O., Neverova, O., \& Bykov, A. (2013). Variability of the anatomical structure of Picea obovata 
Ledeb. Needles under the influence of emissions from the industrial zone of Kemerovo. Contemporary Problems of Ecology, 6, 555-560. https://doi.org/10.1134/S1995425513050065

Li, B., \& Gu, W. C. (2003). Review on genetic diversity in Pinus. Hereditas, 25 (6), 740-748.

Li, C., Chai, B., \& Wang, M. (2008). Population genetic structure of Pinus tabuliformis in Shanxi Plateau, China[J]. Russian Journal of Ecology, 39(1), 34-40. https://doi.org/10.1134/S1067413608010062

Liang, E., Eckstein, D., \& Liu, H. (2008). Climate-growth relationships of relict Pinus tabuliformis at the northern limit of its natural distribution in northern China. Journal of Vegetation Science, 19(3), 393-406. https://doi.org/10.3170/2008-8-18379

Liu, J., Sun, Y., \& Ge, X. (2012). Phylogeographic studies of plants in China: Advances in the past and directions in the future. Journal of Systematics and Evolutio, 50(4), 267-275. https://doi.org/10.1111/j.1759-6831.2012.00214.x

López, R., Climent, J., \& Gil, L. (2010). Intraspecific variation and plasticity in growth and foliar morphology along a climate gradient in the Canary Island pine. Trees, 24, 343-350. https://doi.org/10.1007/s00468-009-0404-2

Mao, J. F., \& Wang, X. R. (2011). Distinct niche divergence characterizes the homoploid hybrid speciation of Pinus densata on the Tibetan Plateau. The American Naturalist, 177, 424-439. https://doi.org/10.1086/658905

Mao, J. F., Li, Y., \& Wang, X. R. (2009). Empirical assessment of the reproductive fitness components of the hybrid pine Pinus densata on the Tibetan. Evolutionary Ecology, 23(3), 447-462. https://doi.org/10.1007/s10682-008-9244-6

Mao, Q. Z., Watanabe, M., \& Imori, M. (2012). Photosynthesis and nitrogen allocation in needles in the sun and shade crowns of hybrid larch saplings: effect of nitrogen application. Photosynthetica, 1-7. https://doi.org/10.1007/s11099-012-0049-z

Meiners, J., \& Winkelmann, T. (2011). Morphological and Genetic Analyses of Hellebore Leaf Spot Disease Isolates from Different Geographic Origins Show Low Variability and Reveal Molecular Evidence for Reclassification into Didymellaceae. Journal of Phytopathology, 159(10), 665-675. https://doi.org/10.1111/j.1439-0434.2011.01823.x

Michael, P., Nobisa, Christopher, T., \& Anita, R. (2012). Latitudinal variation in morphological traits of the genus Pinus and its relation to environmental and phylogenetic signals. Plant Ecology \& Diversity, 5, 1-11. https://doi.org/10.1080/17550874.2012.687501

Nikolić, B., Bojović, S., \& Marin, P. (2013). Variability of morpho-anatomical characteristics of the needles of Picea omorika from natural populations in Serbia. Plant Biosystems, 10, 1080-1126.

Nikolić, B., Bojović, S., \& Marin, P. D. (2013). Variability of morpho-anatomical characteristics of the needles of Picea omorika from natural populations in Serbia. Plant Biosystems, 10, 1080-1126.

Niu, S., W. L. (2013). Open Pollinated Progeny Test and Stability Analysis of Seedlot from Clonal Seed Orchard of Pinus tabuliformis. Journal of Northwest Forestry University, 2, 013.

Nobis, M. P., Traiser, C., \& Roth-Nebelsick, A. (2012). Latitudinal variation in morphological traits of the genus Pinus and its relation to environmental and phylogenetic signals. Plant Ecology \& Diversity, 5(1), 1-11. https://doi.org/10.1080/17550874.2012.687501

Oleksyn, J., Modrzýnski, J., \& Tjoelker, M. G. (1998). Growth and physiology of Picea abies populations from elevational transects: common garden evidence for altitudinal ecotypes and cold adaptation. Functional Ecology, 12(4), 573-590. https://doi.org/10.1046/j.1365-2435.1998.00236.x

Pensa, M., Aalto, T., \& Jalkanen, R. (2004). Variation in needle-trace diameter in respect of needle morphology in five conifer species. Trees-Structure and Function, 18(3), 307-311. https://doi.org/10.1007/s00468-003-0307-6

Rehfeldt, J. (1991). A model of genetic variation for applications in gene resource management. Can J For Res., 2, 1491-1500. https://doi.org/10.1139/x91-209

Schlichting, C. D. (1986). The evolution of phenotypic plasticity in plants. Annual review of ecology and systematics, 17, 667-693. https://doi.org/10.1146/annurev.es.17.110186.003315

Sękiewicz, K., Sękiewicz, M., Jasińska, A., Boratyńska, K., \& Boratyński, A. (2013). Morphological diversity 
and structure of West Mediterranean Abies species. Plant Biosystems, 147, 125-134. https://doi.org/10.1080/11263504.2012.753130

Tiwari, S. P., Kumar, P., Yadav, D., \& Chauhan, D. K. (2013). Comparative morphological, epidermal, and anatomical studies of Pinus roxburghii needles at different altitudes in the North-West Indian Himalayas. Turkish Journal of Botany, 37, 65-73.

Wang, M. B., \& Hao, Z. Z. (2010). Rangewide genetic diversity in natural populations of Chinese pine (Pinus tabuliformis). Biochem Genet, 48(7-8), 590-602. https://doi.org/10.1007/s10528-010-9341-4

Woo, K. S., Fins, L., McDonald, G. I., Wenny, D. L., \& Eramian, A. (2002). Effects of nursery environment on needle morphology of Pinus monticola Dougl. and implications for tree improvement programs. New Forests, 24, 113-129. https://doi.org/10.1023/A:1021230304530

Wu, Y. S., \& Xiao, J. Y. (1991). A preliminary study on vegetation and climate changes in DianChi Lake area in the last 40000 years. Acta Botanica Sinica, 33, 450-458.

Xiao, Y. (2003). Variation in needle longevity of Pinus tabuliformis forests at different geographic scales. Tree Physiology, 23, 463-471. https://doi.org/10.1093/treephys/23.7.463

Xing, F. Q., Mao, J. F., \& Meng, J. X. (2014). Needle morphological evidence of the homoploid hybrid origin of Pinus densata based on analysis of artificial hybrids and the putative parents, Pinus tabuliformis and Pinus yunnanensis. Ecology and Evolution, 4(10), 1890-1902. https://doi.org/10.1002/ece3.1062

Xu, B., \& Tao, W. (2006). Application of a hand-held slicing method for wood species identification. China Wood Ind, 20, 41-43.

Xu, H. C. (1991). Geographical Variation and Selection of Provinces of Pinus tabuliformis. China Forestry Publishing House, Beijing, 21-30.

Yang, L., \& Liu, Z. (2015). Genetic structure of Pinus henryi and Pinus tabuliformis: Natural landscapes as significant barriers to gene flow among populations. Biochemical Systematics and Ecology, 61, 124-132. https://doi.org/10.1016/j.bse.2015.06.003

Yuan, H., \& Li, Z. (2014). Variation and Stability in Female Strobili Production of a First-Generation Clonal Seed Orchard of Chinese Pine (Pinus tabuliformis). Silvae Genetica, 63(1-2), 41-47.

Zhang, S. B., Guan, Z. J., Sun, M., Zhang, J. J., Cao, K. F., \& Hu, H. (2012). Evolutionary association of stomatal traits with leaf vein density in Paphiopedilum, Orchidaceae. Plos One, 7, e40080. https://doi.org/10.1371/journal.pone.0040080

Zhao, C. M., Chen, L. T., Ma, F., Yao, B. Q., \& Liu, J. Q. (2008). Altitudinal differences in the leaf fitness of juvenile and mature alpine spruce trees (Picea crassifolia). Tree Physiology, 28, 133-141. https://doi.org/10.1093/treephys/28.1.133

\section{Copyrights}

Copyright for this article is retained by the author(s), with first publication rights granted to the journal.

This is an open-access article distributed under the terms and conditions of the Creative Commons Attribution license (http://creativecommons.org/licenses/by/4.0/). 